\title{
Analysis of Ladder Chassis of Eicher 20.16 Using FEM
}

\author{
Swami K.I. ${ }^{1}$, Prof. Tuljapure S.B. ${ }^{2}$ \\ ${ }^{1}$ (Student of mechanical engg. W.I.T. solapur, Solapur University, Solapur) \\ 2 (Professor of mechanical engg. W.I.T. solapur, Solapur University, Solapur)
}

\begin{abstract}
The Automotive chassis is considered as the backbone of the vehicle. On chassis different parts are provided with strength, an important consideration in chassis design is to have adequate bending stiffness for better handling characteristics. So, strength and stiffness are two important criteria for the design of the chassis. This paper related with work performed towards the static structural analysis of the truck chassis. Structural systems like the chassis can be easily analyzed using the finite element techniques. So a proper finite element model of the chassis is to be developed. The chassis is modeled in ANSYS. Analysis is done using the same software.
\end{abstract}

Keywords; Ansys, Chassis, Deformation, Pressure, Thickness,

\section{INTRODUCTION}

Chassis usually denotes the basic frame that decides the overall shape of the vehicle. It is aimed at holding important components of the vehicle. Here the chassis of Eicher 20.16 is of ladder frame type which has two side members or longitudinal members of $\mathrm{C}$ - cross section and seven transverse members called cross members of $\mathrm{C}$ - cross section. The chassis has been modeled in Ansys 13 using the most of the actual dimensions. Finite element analysis was done using Ansys 13.

\subsection{Determination of load}

\section{FINITE ELEMENT MODEL VALIDATION}

Model No. $=20.16$

Side bar of the chassis are made from "C" Channels with $230 \mathrm{~mm}$ x $76 \mathrm{~mm}$ x $6 \mathrm{~mm}$

Front Overhang (a) $=1588 \mathrm{~mm}$

Rear Overhang $(\mathrm{c})=2145 \mathrm{~mm}$

Wheel Base (b) $=4800 \mathrm{~mm}$

Material of the chassis is St 52

$\mathrm{E}=2.10 \times 10^{5} \mathrm{~N} / \mathrm{mm}^{2}$

Poisson Ratio $=0.31$

Radius of Gyration $\mathrm{R}=230 / 2=115 \mathrm{~mm}$

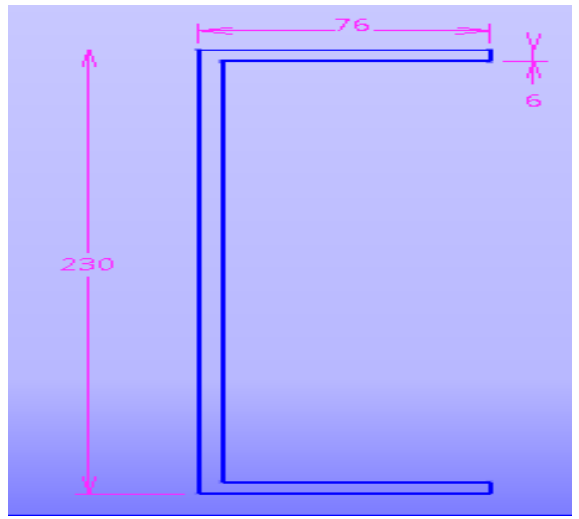

Fig. 2.1 (a) C- section of Side Bar 


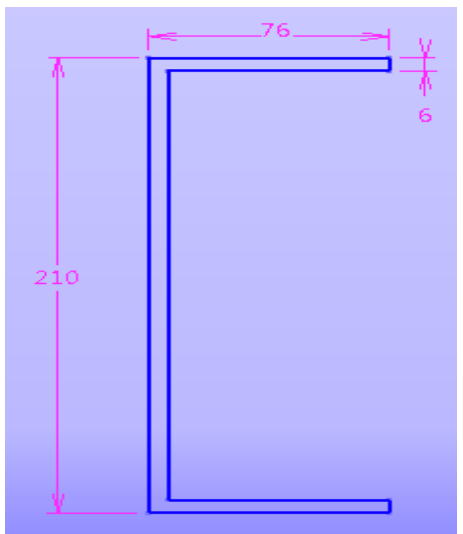

Fig. 2.2 (b) C-section of Cross Bar.

Capacity of Truck $=11400 \mathrm{~kg}=111834 \mathrm{~N}$

Capacity of Truck with $25 \%$ overload $=139792.5 \mathrm{~N}$

Weight of the body and engine $=2700 \mathrm{~kg}=26487 \mathrm{~N}$

Total load acting on chassis $=$ Capacity of the Chassis + Weight of body and engine

$$
\begin{aligned}
& =139792.5+26487 \\
& =166279.5 \mathrm{~N}
\end{aligned}
$$

Chassis has two beams. So load acting on each beam is half of the Total load acting on the chassis.

Load acting on the single beam $=166279.5 / 2$

$$
=83139.75 \mathrm{~N}
$$

For Validation of FEM Model i.e. type of element and mesh density, a cantilever beam is taken of same length as that of main member of chassis also the cross section is same.

2.2 Type of element: - Solid45 is used for the analysis.

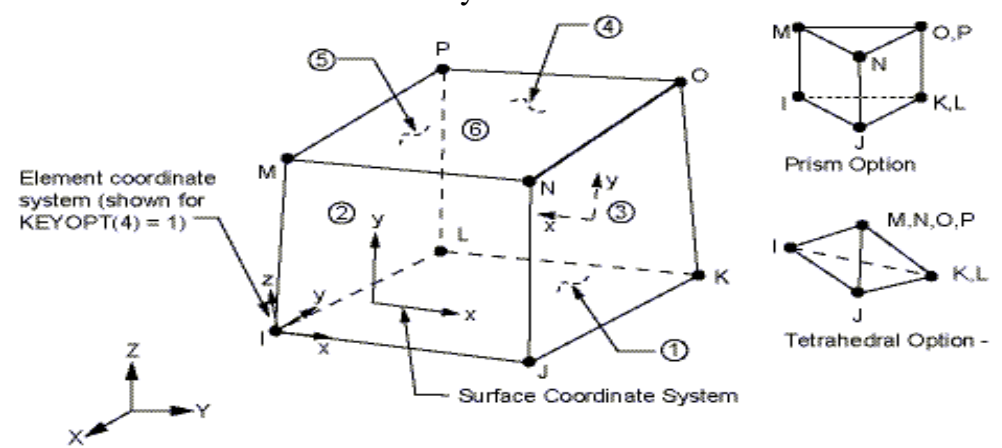

Fig.2.2 solid45 element type

Tab 2.2 Table of Mesh Density

\begin{tabular}{|l|l|}
\hline No. of element & 51614 \\
\hline No. of Nodes & 18824 \\
\hline
\end{tabular}

An arbitrary load of $1 \mathrm{~N} / \mathrm{mm}$ is applied in the form of pressure on the upper face of $\mathrm{C}$ channel is constrained for all DOF at the end is determined using formula.

Deflection of chassis for cantilever beam

$\mathrm{Y}=\left[\left(\mathrm{w} \times 1^{4}\right) /(8 \times \mathrm{E} \times \mathrm{I})\right]$

Where,

$\mathrm{Y}=$ deflection at the free end of beam

$\mathrm{w}=$ Load per unit length

$1=$ Length of beam

$\mathrm{E}=$ Young's modulus of the material of the beam

$\mathrm{I}=$ Area moment of Inertia of beam about an axis passing through its center of gravity 


$$
\begin{aligned}
& =\left[\left(1 \times 8533^{4}\right) /\left(8 \times 2.1 \times 10^{5} \times 16622980\right)\right] \\
& =189.84 \mathrm{~mm}
\end{aligned}
$$

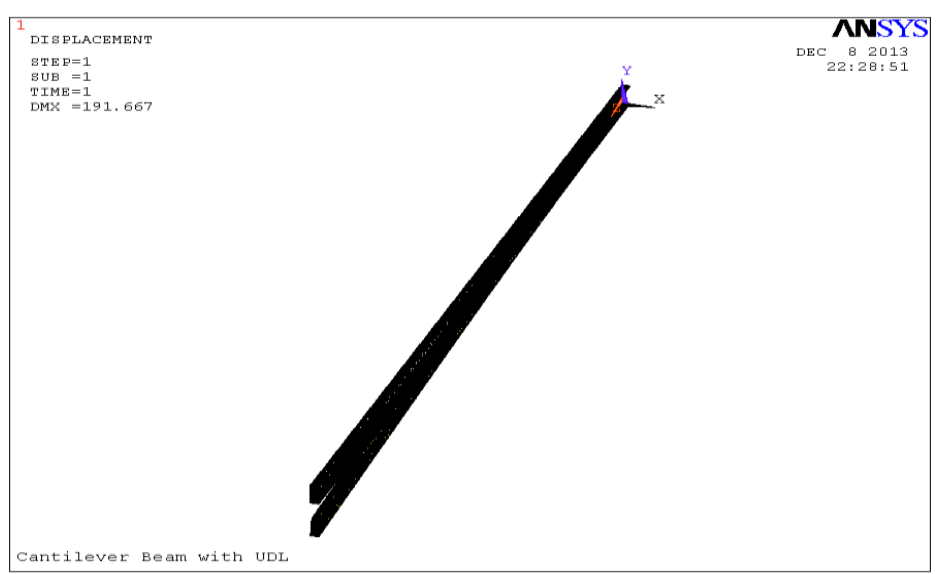

Fig. 2.2(b) Deformation of cantilever beam

The fig. no.2.4 shows deformed shape of cantilever beam with undeformed shape, Deflection obtained by FEM= $191.66 \mathrm{~mm}$

Deflection obtained by Analytical method $=189.84 \mathrm{~mm}$

$$
\begin{aligned}
\text { Error } & =[(191.66-189.84) /(189.84)] \times 100 \\
& =0.959 \%
\end{aligned}
$$

As error is within acceptable limit, mesh density and type of element selected are capable of giving, correct results for whole chassis.

\subsection{Modeling:}

\section{Fem Analysis of chassis}

Simplified model of existing chassis frame is created in ANSYS. The model is shown in Figure.

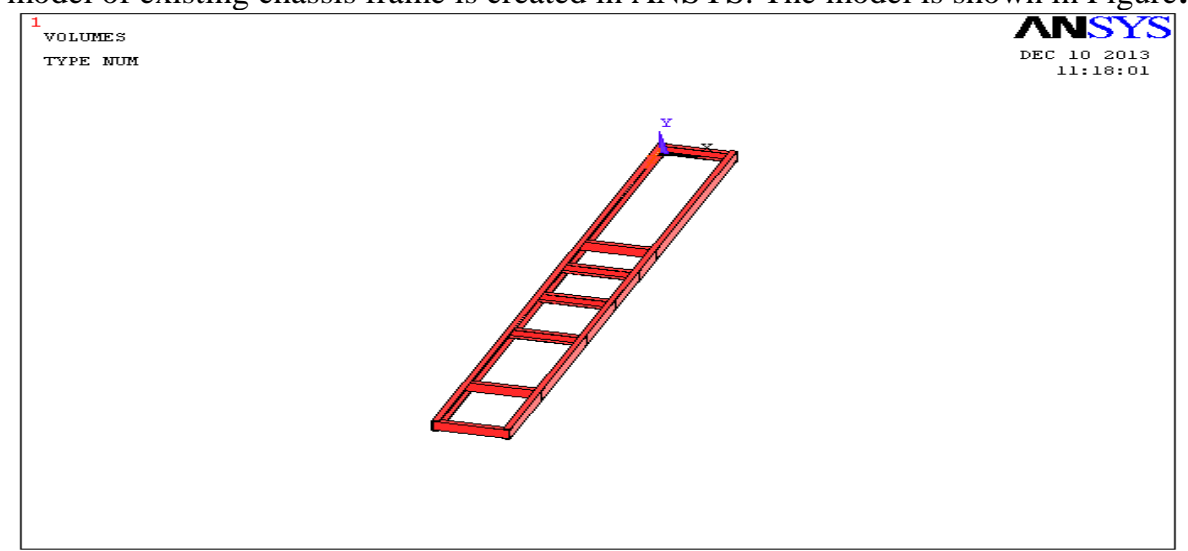

Fig.3.1 Model of chassis frame

\subsection{Loading condition:}

Load condition: - load is applied in the form of pressure on the upper surface of side bars.

$$
\begin{aligned}
\text { Pressure } & =\text { Load } / \text { Area } \\
& =83139.75 / 76 \times 8533 \\
& =0.1282 \mathrm{~N} / \mathrm{mm}^{2}
\end{aligned}
$$

The above pressure is applied on both the side bars 


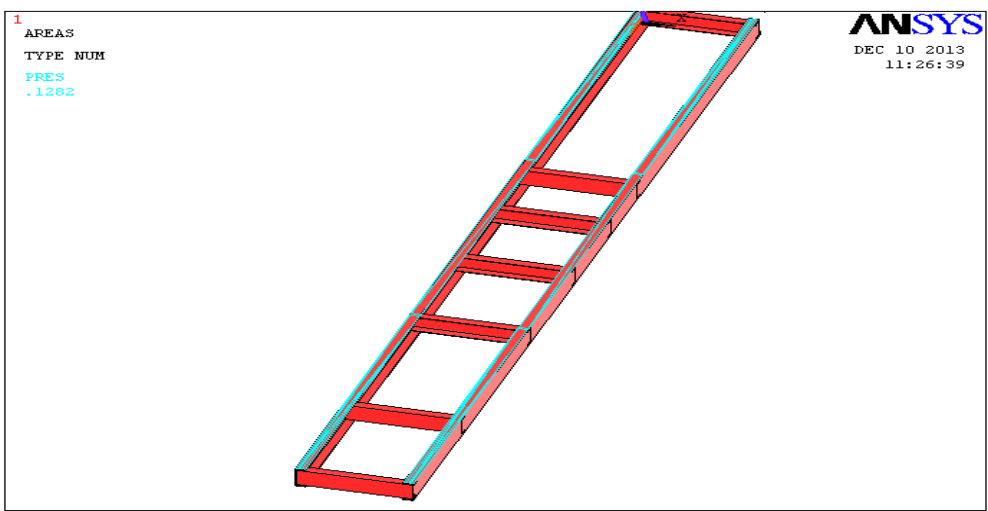

Fig. 3.2 Load condition for chassis frame

(Pressure applied on top faces)

Detail loading of model is shown in Figure.

\subsection{Boundary conditions:}

There are 4 boundary conditions of model; the first two boundary conditions are applied in front of the chassis, the other 2 boundary conditions are applied in rear of chassis, there are shown in Figure. These points on the regions of where leaf springs are fixed on the axle.

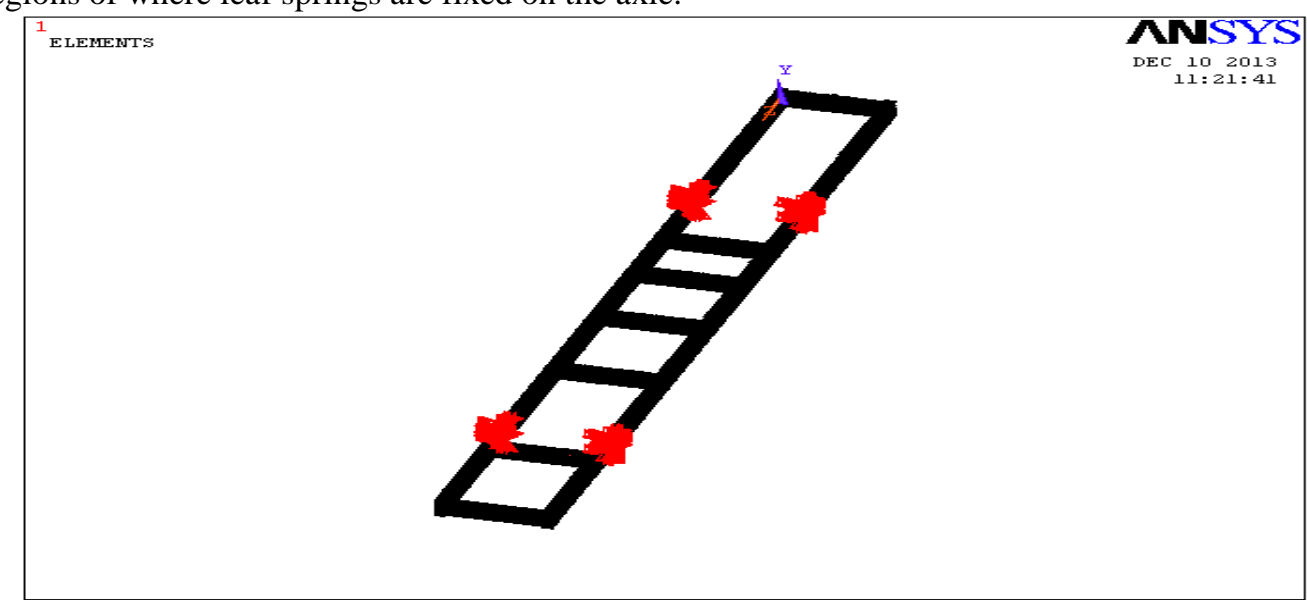

Fig.3.3 Boundary condition for chassis frame

(All DOF constrained at 4 locations)

\subsection{Element and nodes:}

The meshed truck chassis model has 175988 elements and 62005 nodes. The element is tetrahedral.

\subsection{Results:}

The location of Von Mises stress and maximum shear stress are at corner of side bar which in Figure. is 182.994 MPa.

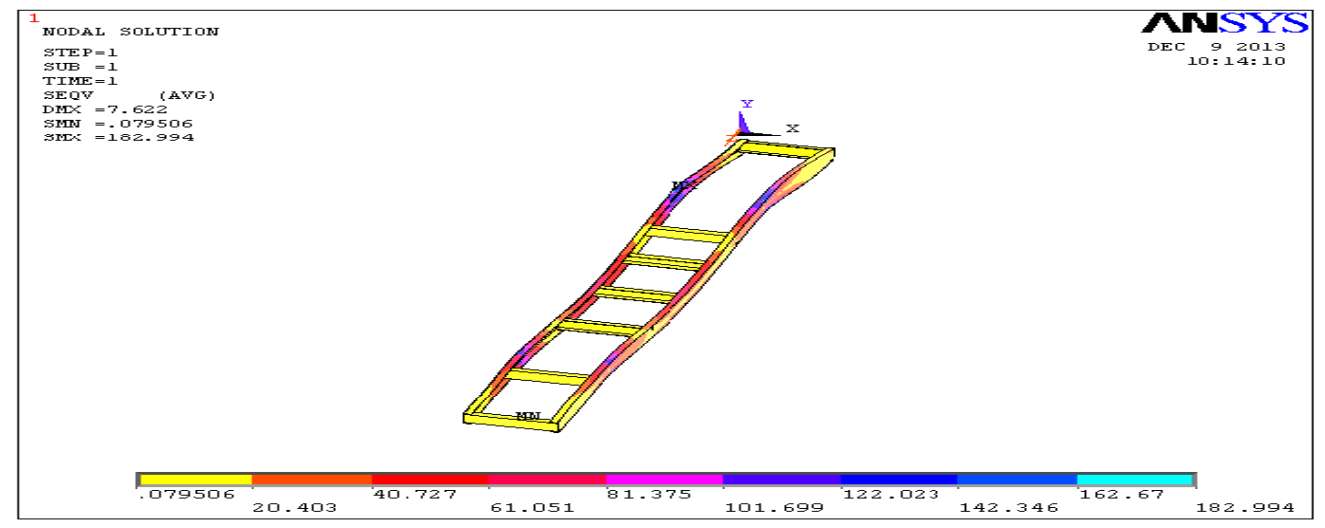

Fig.3.5 (a) von mises stress in chassis 
Von mises stress is more in the region near to rear leaf spring or axle.

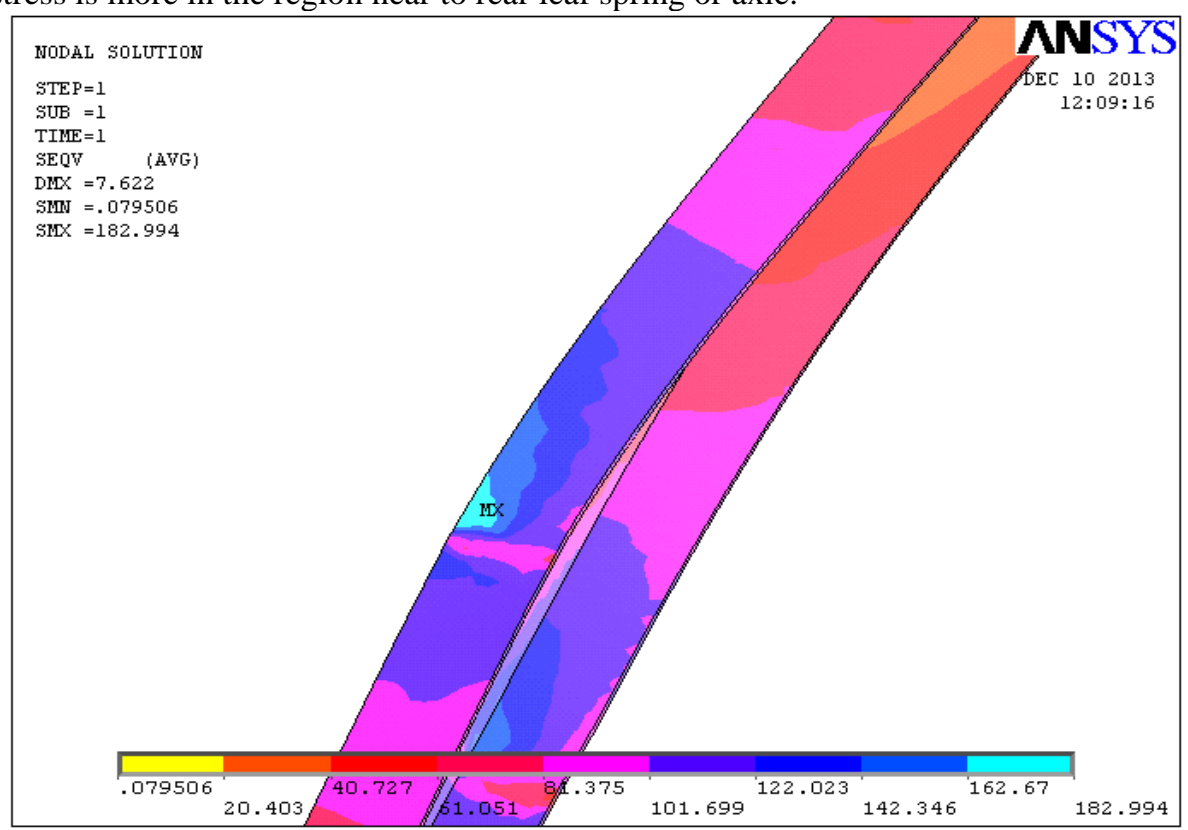

Fig.3.5 (b) maximum von mises stress location

\subsubsection{Displacement}

The displacement of chassis shown in Figure. The magnitude of maximum displacement is $7.622 \mathrm{~mm}$.

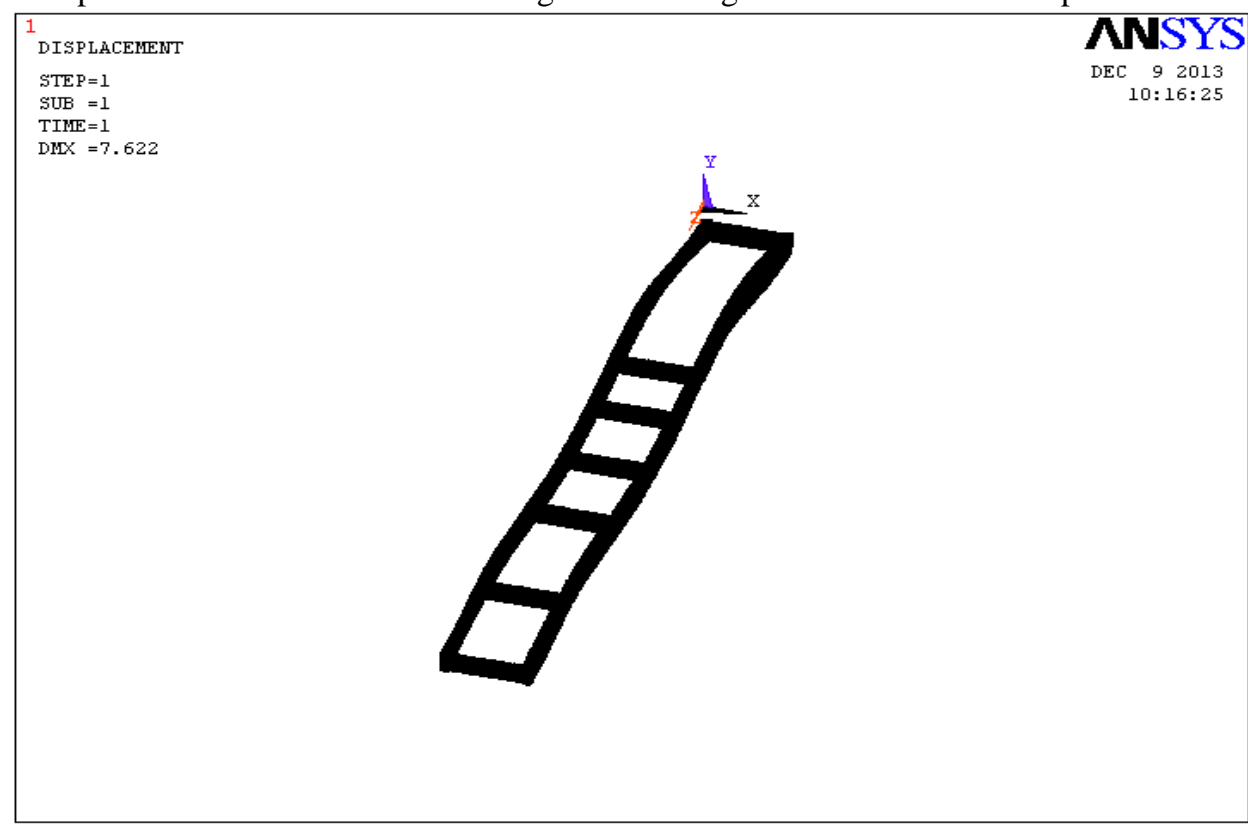

Von mises stress is 182.944

Fig.3.5.1 Deformation in chassis

Deformation is 7.622

\subsection{Effect of varying load:}

Tab no.3.5 varying load

\begin{tabular}{|c|c|c|c|c|}
\hline Sr. no & \% overload & Load(Pressure)N/mm ${ }^{2}$ & $\begin{array}{c}\text { Von mises stress } \\
(\mathrm{MPa})\end{array}$ & $\begin{array}{c}\text { Deformation } \\
(\mathrm{mm})\end{array}$ \\
\hline 1 & 5 & 0.1109 & 158.3 & 6.593 \\
\hline 2 & 10 & 0.1152 & 164.438 & 6.849 \\
\hline 3 & 15 & 0.1195 & 170.576 & 7.104 \\
\hline 4 & 20 & 0.12839 & 176.842 & 7.365 \\
\hline 5 & 25 & 0.1282 & 182.994 & 7.622 \\
\hline
\end{tabular}




\section{Pressure vs. Deformation}

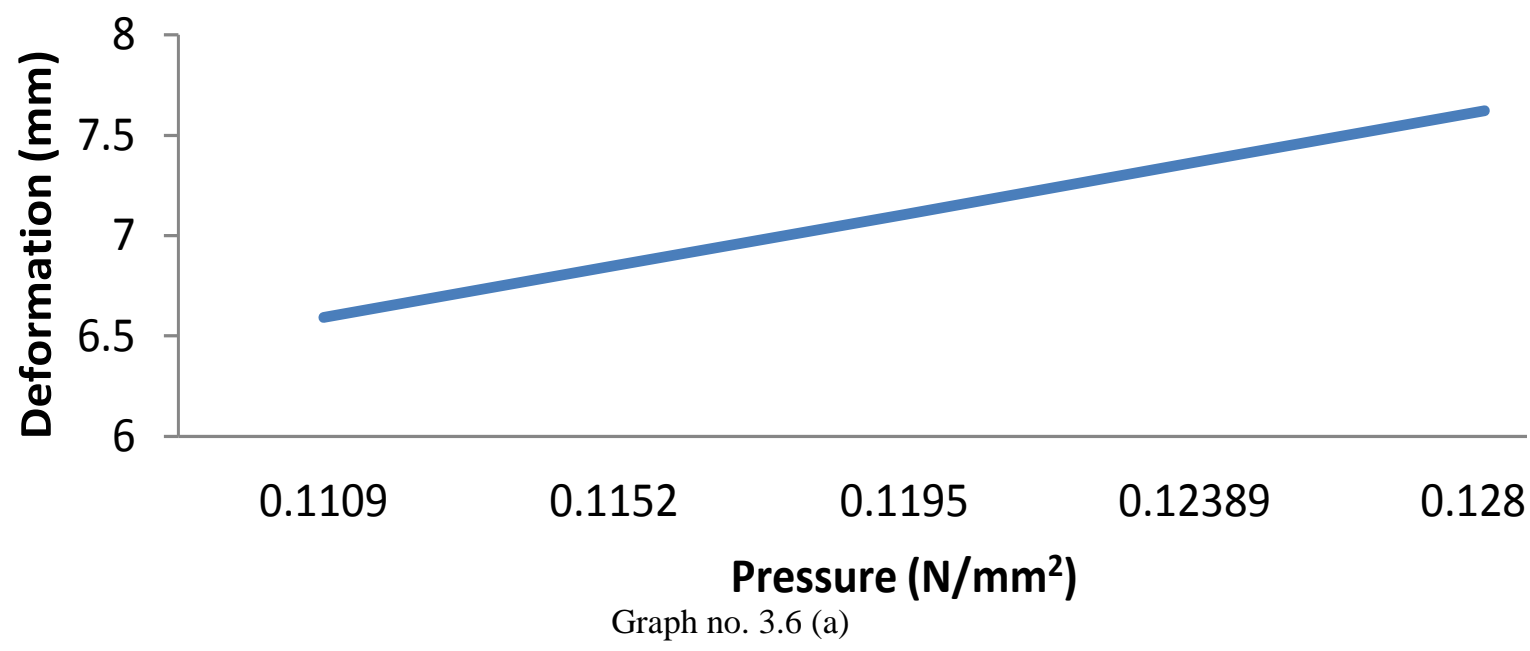

\section{Pressure Vs. Von Mises Stress}

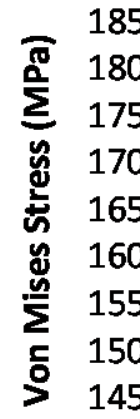

0.1109

0.1152

0.1195

0.12389

0.1282

Graph no.3.6 (b)

From the above graph, it is seen that there is straight line relationship between the load \& maximum deformation. As load increases, maximum deformation increases. Also maximum Von Mises stress value increases proportionately with the increase in the Pressure value.

\subsection{Effect of side member thickness:}

During this study, variation of Side member thickness thickness is done to observe its effect on the stresses \& deformation.

Table 3.7 Effect of Side member thickness

\begin{tabular}{|c|c|c|c|}
\hline $\begin{array}{c}\text { Sr. } \\
\text { No. }\end{array}$ & Side member thickness (mm) & Max. Deformation (mm) & $\begin{array}{c}\text { Max. Stress (MPa) } \\
\text { Von Mises }\end{array}$ \\
\hline 1 & 5 & 6.048 & 179.542 \\
\hline 2 & 5.5 & 6.846 & 175.776 \\
\hline 3 & 6 & 7.750 & 201.304 \\
\hline 4 & 6.5 & 8.203 & 173.789 \\
\hline 5 & 7 & 8.900 & 182.993 \\
\hline
\end{tabular}
Chassis.

The following graph shows the relationship between Side member thickness \& maximum deformation of 


\section{Thickness vs. Deformation}

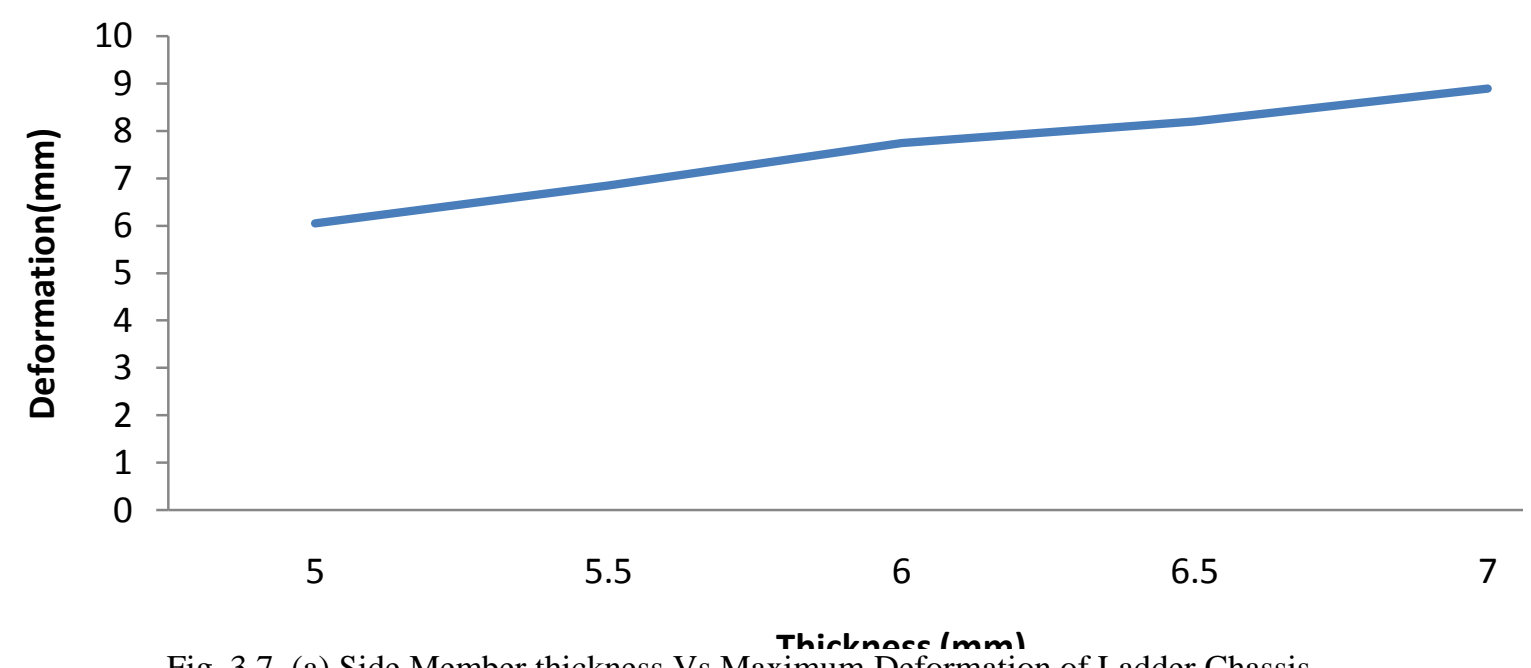

Fig. 3.7. (a) Side Member thickness Vs Maximum Deformation of Ladder Chassis

From the above graph, it is seen that as there is increase in the Side member thickness, there is small increase in the maximum deformation of the Side member after a certain value of Side member thickness, there is again increase in the maximum deformation of the beam, with increase in thickness.

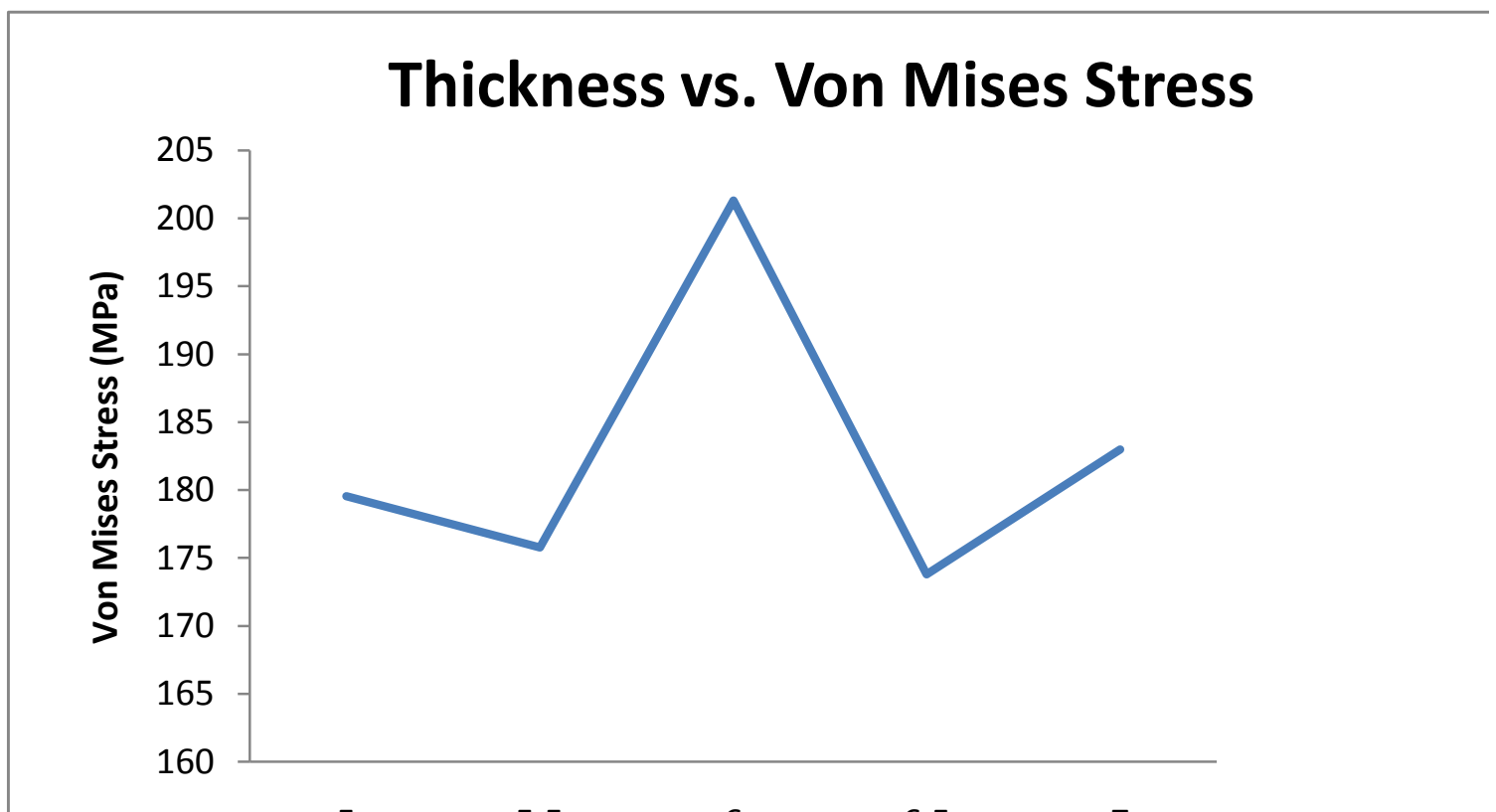

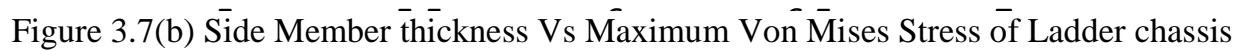

From the graph, it is seen that as Side member thickness decreases, initially there is decrease in the Maximum value of Von Mises stress but afterwards it starts increasing. The rate decreases in just before the end $\&$ again increases at the end.

\section{Conclusion}

- From Graph it shows that as load increases deformation increases.

- From Graph it shows that as load increases von misses stress increases.

- As the Side member thickness increases, deformation increases but this increase is uniform.

- As the Side member thickness increases, initially there is decrease in the Maximum value of Von Mises stress but afterwards it starts increasing. The rate decreases in just before the end \& again increases at the end. 


\section{REFERENCES}

[1] Vijaykumar V. Patel and R. I. Patel, "Structural analysis of a ladder chassis frame", World Journal of Science and Technology 2012, 2(4):05-08 ISSN: $2231-2587$

[2] M. Ravi Chandra, S. Sreenivasulu \& Syed Altaf Hussain, "Modeling And Structural Analysis Of Heavy Vehicle Chassis Made Of Polymeric Composite Material By Three Different Cross Sections", Journal of Mechanical and Production Engineering Research and Development (IJMPERD), ISSN 2249-6890, Vol.2, Issue 2,Sep 2012 45-60.

[3] I. D. Paul, S. M. Sarange, G. P. Bhole And J. R. Chaudhari, "Structural Analysis Of Truck Chassis Using Finite Element Method", International J.of Multidispl.Research \& Advcs. in Engg.(IJMRAE), ISSN 0975-7074, Vol. 4, No. I (January 2012), pp. 85-98

[4] M. Zehsaz et al "The effect of Connection-Plate Thickness on Stress of Truck Chassis with Riveted and Welded Joints under Dynamic Loads", Asian J. of Applied sciences, ISSN 1996-3343, VOl. 2, No.1 (2009),pp.22-35

[5] Manpreet Singh Bajwa, Sinthya Pundir, Amit Joshi "Static Load Analysis of TATA Super Ace Chassis And Stress Optimisation Using Standard Techniques",International J of Mechanical And Production Engineering. ISSN: 2320-2092,vol-1, No.2(Aug-2013).

[6] Joseph Edward Shigley, Charles R. Mischke "Mechanical Engineering Design", McGraw-Hill Book Company, New York, 2000, Sixth Edition

[7] M. F. Spotts, "Design of Machine Elements", Prentice Hall of India Pvt. Ltd, New delhi, 2004.

[8] Reddy J.N, “An Introduction to Finite Element Method", Tata McGraw-Hill Publication, Fifth Edition. 